\title{
Endocardite por Coxiella burnetii (febre Q). Doença rara ou pouco diagnosticada? Relato de caso
}

\author{
Endocarditis due to Coxiella burnetii ( $\mathrm{Q}$ fever). \\ A rare or underdiagnosed disease? Case report
}

\author{
Rinaldo Focaccia Siciliano ${ }^{1}$, Henrique Barbosa Ribeiro ${ }^{1}$, Remo Holanda de Mendonça Furtado ${ }^{1}$, \\ Jussara Bianchi Castelli ${ }^{1}$, Roney Orismar Sampaio ${ }^{1}$, Fabiana Cristina Pereira dos Santos ${ }^{2}$, \\ Silvia Colombo ${ }^{2}$, Max Grinberg ${ }^{1}$ e Tânia Mara Varejão Strabelli ${ }^{1}$
}

\begin{abstract}
RESUMO
A febre Q é uma zoonose de distribuição mundial causada por Coxiella burnetii, sendo raros os registros da doença no Brasil. Estudos soroepidemiológicos mostraram uma frequiência relativamente elevada de anticorpos contra Coxiella burnetii em populações com exposição ocupacional. Em humanos, pode se manifestar clinicamente como doença aguda ou crônica, sendo que a endocardite é a forma crônica mais freqüente da febre Q e de maior morbi-mortalidade. Relatamos um caso grave de endocardite por Coxiella burnetii adquirida no Brasil com desfecho fatal, apesar de antibioticoterapia adequada e tratamento cirúrgico valvar.
\end{abstract}

Palavras-chaves: Endocardite. Coxiella burnetii. Febre Q. Insuficiência aórtica.

\begin{abstract}
Q fever is a zoonosis of worldwide distribution that is caused by Coxiella burnetii. However, reports of this disease in Brazil are rare. Seroepidemiological studies have shown relatively high frequencies of antibodies against Coxiella burnetii in populations with occupational exposure. In humans, it can be manifested clinically as acute or chronic disease. Endocarditis is the most frequent chronic form of $Q$ fever and the form with the greatest morbidity and mortality. We report a severe case of endocarditis due to Coxiella burnetii acquired in Brazil that had a fatal outcome, despite specific antibiotic therapy and valve surgery treatment.
\end{abstract}

Key-words: Endocarditis. Coxiella burnetii. Q fever. Aortic insufficiency.

A febre Q, causada pela Coxiella burnetii, agente infeccioso antes incluído no grupo das riquétsias e, atualmente, definido como uma bactéria com similaridade à Legionella, é uma zoonose encontrada em todos os continentes e que pode se manifestar com um amplo espectro clínico em humanos. A febre $Q$ aguda, na maioria das vezes, é oligossintomática, semelhante a uma síndrome gripal. Uma minoria desenvolve pneumonia, hepatite ou febre prolongada, podendo requerer hospitalização. Em alguns indivíduos a infecção adquire uma evolução crônica, como endocardites, osteomielites ou infecções vasculares. A endocardite é a expressão clínica mais freqüente da doença crônica (cerca de $70 \%$ dos casos), tem elevada letalidade quando não tratada e acomete sobretudo aqueles com doença valvar preexistente 9 .

A exata prevalência desta endocardite não é conhecida. Estudos realizados em pacientes com endocardite com hemoculturas negativas em um hospital da Inglaterra e num centro de referência de riquetsioses na França, revelaram a Coxiella burnetii como responsável por 12\% e 48\% dos casos, respectivamente ${ }^{56}$. No Brasil, embora existam evidências soroepidemiológicas de infecção pregressa entre populações expostas, somente nos últimos anos foram relatados os primeiros casos de Febre Q, incluindo endocardites ${ }^{316}{ }^{17}$. Por se tratar de um microorganismo intracelular obrigatório, não é cultivável nos meios tradicionais de hemoculturas que assim resultam negativas. Além disso, o comportamento clínico e ecocardiográfico diferem das endocardites causadas por outras bactérias, o que dificulta sobremaneira a suspeita do diagnóstico.

Relatamos a seguir um caso grave de endocardite por Coxiella burnetii autóctone do Estado da Bahia, que apresentou desfecho fatal.

\footnotetext{
1. Instituto do Coração, Hospital das Clínicas, Faculdade de Medicina, Universidade de São Paulo, São Paulo-SP. 2. Setor de Riquétsias, Instituto Adolfo Lutz, São Paulo, SP. Endereço para correspondência: Dr. Rinaldo Focaccia Siciliano. Rua Cardoso de Almeida 1006/13, Perdizes, 05013-001 São Paulo, SP.

Tel. $55113069-5358$

email: rinaldo_focaccia@uol.com.br

Recebido para publicação em 07/02/2008

Aceito em 02/07/2008
} 


\section{RELATO DE CASO}

Homem de 41 anos, natural e procedente de São Felipe (Bahia), admitido com história de dispnéia progressiva aos esforços no último ano, evoluindo há um mês com dispnéia paroxística noturna, edema de membros inferiores e sudorese vespertina. Associava-se ao quadro fadiga, limitação significativa à realização de suas atividades e emagrecimento de cerca de cinco quilos nos últimos três meses. Como antecedentes apresentava tabagismo (um maço/dia, há 20 anos), tendo interrompido havia um mês. Trabalhava na lavoura e com gado bovino, além de ingerir leite cru e seus derivados, habitualmente.

Ao exame físico de admissão no pronto atendimento, o paciente apresentava-se em regular estado geral, emagrecido, afebril $\left(36,7^{\circ} \mathrm{C}\right)$, normotenso, eupneico e com frequiência cardíaca de 90 batimentos por minuto, rítmica. À ausculta pulmonar, evidenciavamse estertores crepitantes em bases. Ao exame cardiovascular, apresentava pulso em martelo d'água, ictus palpável com duas polpas digitais, no $6^{\circ}$ espaço intercostal esquerdo; sopro sistólico ejetivo 3+/6+ e diastólico 4+/6+, ambos em foco aórtico, além de sopro deAustin-Flint. Também foi identificado sopro holossistólico 3+/6+ em área mitral. A palpação do abdome revelou significativa hepatoesplenomegalia. Extremidades com baqueteamento digital e edema periférico discreto.

Os eletrólitos séricos, bilirrubinas e a função renal eram normais. Aspartato aminotransferase de 75U/L, alanina aminotransferase de $76 \mathrm{U} / \mathrm{L}$, albumina sérica de $2,6 \mathrm{~g} / \mathrm{dL}$, com aumento da fração gama na eletroforese de proteínas $(2,4 \mathrm{~g} / \mathrm{dL})$. As provas de atividade inflamatórias apresentaram velocidade de eritrossedimentação de $47 \mathrm{~mm}$ na $1^{\mathrm{a}}$ hora e proteína $\mathrm{C}$ reativa de $2,07 \mathrm{mg} / \mathrm{dL}$ (controle $0,5 \mathrm{mg} / \mathrm{dL}$ ). Peptídeo natriurético do tipo $\mathrm{B}$ foi de $2.653 \mathrm{pg} / \mathrm{ml}$. O hemograma mostrava anemia normocítica e hipocrômica com diferencial de leucócitos e plaquetas normais. Amostra de urina obtida foi positiva para proteínas $(0,6 \mathrm{~g} /)$. Foram colhidos três pares (aeróbio/anaeróbio) de hemoculturas periféricas que resultaram negativas.

A radiografia de tórax evidenciou cardiomegalia e sinais de congestão pulmonar. 0 eletrocardiograma apresentava ritmo sinusal, bloqueio da divisão ântero-superior esquerda, com sobrecarga de câmaras esquerdas. 0 ecocardiograma transesofágico mostrou ventrículo esquerdo dilatado (diâmetro diastólico de 72mm), com função preservada (fração de ejeção de $71 \%$ ). A valva aórtica apresentava dupla disfunção com insuficiência severa e estenose discreta. Além disso, o ventrículo direito apresentava hipocinesia moderada e pressão estimada de artéria pulmonar de $75 \mathrm{mmHg}$.

A microimunofluorescência indireta (antifase I) para Coxiella burnetii foi positiva, com títulos maiores que 1/1.600 e < 400 para Bartonella henselae e Bartonella quintana. Iniciouse antibioticoterapia com doxiciclina e ciprofloxacina pela possibilidade de endocardite por Coxiella burnetii.

o paciente evoluiu, inicialmente, com ganho de peso e melhora do estado geral. Entretanto, a partir da terceira semana da antibioticoterapia, retornaram os sintomas de insuficiência cardíaca, além de febre baixa e astenia. Novas hemoculturas foram colhidas, que permaneceram negativas, assim como uma urocultura. Na ausência de novo foco infeccioso, decidiu-se pelo tratamento cirúrgico valvar.

Durante 0 ato operatório, o aspecto macroscópico da válvula aórtica era de calcificação e sinais degenerativos em valva possivelmente bicúspide (Figura 1a), com dilatação do seio coronário e formação de neocavidade relacionada lateralmente à

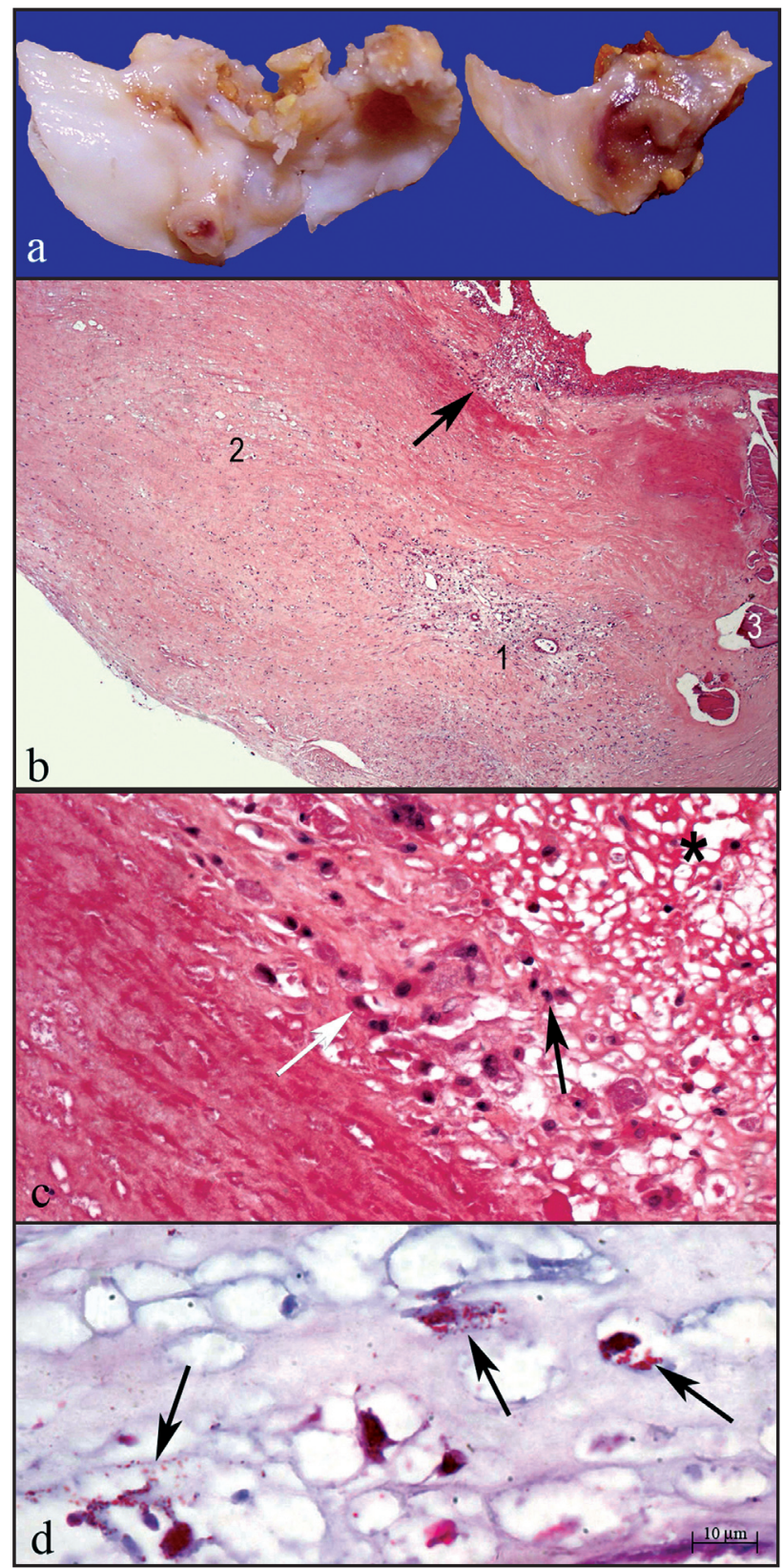

Hematoxilina \& eosina, com objetiva de 5X e 40X, respectivamente, e coloração de Gimenez, com objetiva de imersão de 100X.

Figura 1 - Imagens do exame anatomopatológico valvar. a) Macroscopia dos fragmentos da valva aórtica. Note o espessamento e a irregularidade importantes das semilunares aórticas. b) Histologia valvar evidenciando a endocardite crônica, com áreas de neoformação vascular e infiltrado mononuclear (1), acentuado espessamento por fibrose (2) e calcificação distrófica inicial multifocal (3) nas semilunares. A seta indica área mostrada em maior aumento na próxima imagem. c) Região valvar mais superficial com infiltrado mononuclear composto principalmente por macrófagos (um deles apontado pela seta branca), raros neutrófilos (seta preta) e deposição superficial de fibrina (*), indícios de atividade no processo. d) Microorganismos na forma cocóide ou cocobacilar, consistentes com Coxiella burnetii, são observados no interior de macrófagos. 
cúspide coronariana direita. Havia, ainda, vegetação na face ventricular aderida à região correspondente à cúspide não-coronariana. A valva mitral mostrava dilatação do anel e falha de coaptação das cúspides, sem sinais de endocardite. As valvas não apresentavam padrão macroscópico de doença reumática, tais como fusão de comissuras e espessamento de cordoalha. Foi realizada troca da valva aórtica por prótese biológica, plástica da valva mitral com anel posterior e correção do aneurisma do seio de Valsalva.

A histologia valvar revelou intensa fibrose, calcificação distrófica multifocal, neoformação vascular pericalcificação e infiltrado mononuclear (Figura 1b). Havia ainda, vegetações de exsudato fibrino-leucocitário, algumas com organização na base representada por vasos neoformados e infiltrado mononuclear com predomínio de macrófagos, sugestivos de endocardite em organização (Figura 1c). As colorações histoquímicas para agentes infecciosos usuais (Brown-Hopps, prata metenamina de Grocott e Ziebl-Neelsen) resultaram negativas. A coloração de Gimenez demonstrou a presença de bactérias pequenas, de forma cocóide ou cocobacilar, no citoplasma de macrófagos (Figura 1d). A conclusão diagnóstica foi de valvopatia crônica de padrão degenerativo em valva aórtica possivelmente bicúspide, associada à endocardite infecciosa crônica com sinais de atividade suscitada pela presença de agente infeccioso intracelular consistente com Coxiella burnetii.

No pós-operatório imediato, houve sangramento intenso, sendo indicada nova intervenção cirúrgica para revisão de hemostasia, que detectou sangramento secundário à deiscência de atriotomia. Após 48 horas do pós-operatório o paciente foi extubado, porém apresentou acentuada piora clínica, compatível com choque séptico de provável origem pulmonar, sendo, então associado cefepima e vancomicina. № $5^{\circ}$ pós-operatório, houve piora do choque, agora refratário a aminas vasoativas, $\mathrm{e}$ insuficiência de múltiplos órgãos, falecendo no dia seguinte. A necropsia não foi realizada por recusa da família.

\section{DISCUSSÃO}

Apesar de ser considerada uma zoonose de distribuição mundial, há poucos relatos de febre Q no Brasil. Alguns estudos pioneiros de soroprevalência realizados nas décadas de 60 e 70 revelaram a presença de anticorpos contra Coxiella burnetii em taxas relativamente altas, entre indivíduos potencialmente expostos. No Estado de São Paulo, uma avaliação de trabalhadores da zona rural e da indústria na zona urbana encontrou soropositividade em baixos títulos de anticorpos em 8,5\% e $0,5 \%$, respectivamente ${ }^{12}$. Em Minas Gerais, foram observadas taxas de soroprevalência de $22 \%$ entre veterinários ${ }^{14}, 29 \%$ entre trabalhadores de abatedouro ${ }^{13}$ e 3,9\% em um estudo recente entre moradores de uma comunidade rural mineira ${ }^{2}$.

Embora com limitações, estes dados sugerem exposição prévia a Coxiella burnetii e a possibilidade da ocorrência de doença (febre Q) em nosso país. No entanto, somente em 2006, Costa e cols ${ }^{3}$ descreveram a primeira série com quinze casos de febre Q de comportamento clínico e sorológico compatível com doença aguda, e um de doença crônica (espondilodiscite).
Quanto à endocardite causada por Coxiella burnetii encontramos na literatura indexada no Medline (www.ncbi.nlm.nih.gov/sites/ entrez) apenas quatro casos da doença (incluindo o caso atual) que foram diagnosticados em nosso instituto ${ }^{16}{ }^{17}$. Os pacientes eram provenientes de regiões distintas do país e todos tinham contato quotidiano com gado bovino e ingestão de leite cru (Vale do Ribeira-SP, Marabá-PA, Capim Grosso-BA e São Felipe-BA).

A transmissão da Coxiella burnetii ocorre pela inalação de aerossóis contaminantes derivados de secreções orgânicas do gado (reservatório primário), principalmente durante o parto, ou através da ingestão de leite cru contaminado. A maioria dos pacientes com endocardite por Coxiella burnetii apresenta valvopatia prévia (até 90\%), hemoculturas negativas e evolução insidiosa dos sintomas de insuficiência cardíaca progressiva e/ou sintomas inespecíficos como fadiga, perda de peso, suor noturno e febre baixa ${ }^{19}{ }^{18}$. Assim, a infecção pode assumir um comportamento crônico, bastante diferente da evolução agudasubaguda da endocardite clássica, o que torna a suspeição clínica menos provável. A média de tempo entre o início dos sintomas e o diagnóstico de endocardite por Coxiella burnetii pode ser tão longo quanto cinco a 18 meses $^{18}$.

Ao exame físico há evidência de hepato-esplenomegalia, baqueteamento digital, rash secundário a vasculites em extremidades e fenômenos embólicos que podem ocorrer em cerca de $20 \%$ dos $\operatorname{cas}^{9}{ }^{918}$. Os achados laboratoriais mais frequientes são de infecção sistêmica crônica, como anemia, plaquetopenia, aumento de gamaglobulinas, aminotransferases, desidrogenase láctica e $\mathrm{VHS}^{918}$.

Uma dificuldade diagnóstica adicional é o fato desta forma de endocardite cursar com vegetações nodulares, pequenas ou planas que podem passar despercebidas mesmo na ecocardiografia transesofágica ${ }^{11}{ }^{18}$. Na prática clínica, o exame mais simples para o diagnóstico etiológico é a microimunofluorescência indireta, disponível em centros de referência para riquetsioses no Brasil. Títulos de IgG antifase-I maiores ou iguais a 1:800 constituem marcador diagnóstico da infecção crônica, com elevada especificidade e sensibilidade ${ }^{4}$. A presença da Coxiella burnetii na vegetação valvar pode ser confirmada por biologia molecular, imunohistoquímica ou isolamento em cultura celular ${ }^{8}$.

0 exame histológico continua sendo o padrão ouro no diagnóstico de endocardite infecciosa causada por bactérias usuais. No entanto, isto pode ser difícil nas endocardites causadas por tais agentes intracelulares fastidiosos ${ }^{7}$. A valvopatia preexistente, que é encontrada na maioria dos pacientes acometidos, pode obscurecer o diagnóstico histológico de endocardite pela sobreposição de alterações. Os achados mais freqüentes são vegetações pequenas ou ausentes, neovascularização e inflamação (principalmente linfócitos e macrófagos, discretos e localizados), remodelagem importante do tecido valvar às custas de fibrose e calcificação, possivelmente devido ao estímulo inflamatório crônico e repetido dos agentes intracelulares ${ }^{8}$. 0 diagnóstico histológico de endocardite pode passar despercebido pelas características passíveis de confusão com processos degenerativos, que também cursam com fibrose, calcificação, vasos neoformados (pericalcificação) e inflamação crônica $^{78}$. 
Adicionalmente, além do reconhecimento do padrão inflamatório, há dificuldade em se identificar a presença da Coxiella burnetii pelos métodos habituais de pesquisa histológica de microorganismos. Apesar de, em certa medida, serem semelhantes aos bacilos Gram negativos, estes se coram muito mal, ou absolutamente não coram, pela coloração tecidual similar ao Gram (Brown-Hopps). Por outro lado, podem ser identificados pelo método de Gimenez, como a Legionella spp e as riquétsias, o que pode auxiliar o diagnóstico histológico.

0 tratamento desta endocardite deve ser prolongado, pois há dificuldade na erradicação da Coxiella burnetii da vegetação, o que requer meses de terapia. Outra particularidade é que a Coxiella burnetii é resistente aos antibióticos habitualmente empregados de forma empírica em endocardites com hemoculturas negativas, como a associação de $\beta$-lactâmicos com aminoglicosídeo. A doxiciclina associada à hidroxicloroquina parece ser o esquema terapêutico mais curto e eficaz (18 meses de tratamento $)^{10}$, embora necessite de acompanhamento regular pela sua toxicidade ocular. Outra opção terapêutica é a associação de doxiciclina e uma fluoroquinolona, entretanto, este esquema terapêutico necessita ser mantido por até quatro anos. Esquemas de monoterapia com macrolídeos têm boa resposta inicial, mas apresentam alto risco de recidiva após sua suspensão9.

0 paciente em questão apresentou-se ao hospital já em estágio avançado de desnutrição e disfunção cardíaca, provavelmente secundárias à infecção valvar crônica por Coxiella burnetii (um ano de evolução). Embora existam evidências de resistência da Coxiella burnetii à doxiciclina ${ }^{15}$, é possível que a progressão da disfunção valvar e a persistência da febre a despeito do tratamento antibiótico específico decorreram do diagnóstico tardio, culminando com necessidade de troca valvar de urgência para controle do foco infeccioso. Neste contexto de vulnerabilidade, 0 óbito decorreu de choque séptico de foco pulmonar no período pós-operatório precoce.

Em conclusão, relatamos um caso de endocardite por febre $Q$ adquirida no Brasil, que apresentou desfecho fatal. Em função das evidências soroepidemiológicas, da possibilidade de infecção por Coxiella burnetii e das dificuldades enfrentadas para o diagnóstico etiológico de casos de endocardite, por este microorganismo, acreditamos que esta seja uma doença pouco diagnosticada e possivelmente subnotificada em nosso país.

\section{REFERÊNCIAS}

1. Brouqui P, Raoult D. Endocarditis due to rare and fastidious bacteria. Clinical Microbiology Reviews 14: 177-207, 2001.
2. Costa PS, Brigatte ME, Greco DB. Antibodies to Rickettsia rickettsii, Rickettsia typhi, Coxiella burnetii, Bartonella benselae, Bartonella quintana, and Ehrlichia chaffeensis among healthy population in Minas Gerais, Brazil. Memórias do Instituto Oswaldo Cruz 100: 853-859, 2005.

3. Costa PS, Brigatte ME, Greco DB. Questing one Brazilian query: reporting 16 cases of Q fever from Minas Gerais, Brazil. Revista do Instituto de Medicina Tropical de São Paulo 48: 5-9, 2006.

4. Dupont HT, Thirion X, Raoult D. Q fever serology: cutoff determination for microimmunofluorescence. Clinical and Diagnostic Laboratory Immunology 1: 189-196, 1994.

5. Houpikian P, Raoult D. Blood culture-negative endocarditis in a reference center: etiologic diagnosis of 348 cases. Medicine (Baltimore) 84: 162-173, 2005.

6. Lamas CC, Eykyn SJ. Blood culture negative endocarditis: analysis of 63 cases presenting over 25 years. Heart 89: 258-262, 2003.

7. Lepidi H, Durack DT, Raoult D. Diagnostic methods current best practices and guidelines for histologic evaluation in infective endocarditis. Infectious Disease Clinics of North America 16: 339-361, ix, 2002.

8. Lepidi H, Houpikian P, Liang Z, Raoult D. Cardiac valves in patients with Q fever endocarditis: microbiological, molecular, and histologic studies. The Journal of Infectious Diseases 187: 1097-1106, 2003.

9. Maurin M, Raoult D. Q fever. Clinical Microbiology Reviews 12: 518-553, 1999.

10. Raoult D, Houpikian P, Tissot Dupont H, Riss JM, Arditi-Djiane J, Brouqui P. Treatment of $Q$ fever endocarditis: comparison of 2 regimens containing doxycycline and ofloxacin or hydroxychloroquine. Archives of Internal Medicine 159: 167-173, 1999.

11. Raoult D, Marrie T. Q fever. Clinical Infectious Diseases 20: 489-495; quiz 496, 1995.

12. Ribeiro-Neto A, Nikitin T, Ribeiro IF. Estudo sobre a febre Q em São Paulo. III. Prevalência em ordenhadores e tratadores de bovinos. Revista do Instituto de Medicina Tropical de São Paulo 6: 255-257, 1964.

13. Riemann HP, Brant PC, Behymer DE, Franti CE. Toxoplasma gondii and Coxiella burneti antibodies among Brazilian slaughterhouse employees. American Journal of Epidemiology 102: 386-393, 1975.

14. Riemann HP, Brant PC, Franti CE, Reis R, Buchanan AM, Stormont C, Behymer DE. Antibodies to Toxoplasma gondii and Coxiella burneti among students and other personnel in veterinary colleges in California and Brazil. American Journal of Epidemiology 100: 197-208, 1974.

15. Rolain JM, Boulos A, Mallet MN, Raoult D. Correlation between ratio of serum doxycycline concentration to MIC and rapid decline of antibody levels during treatment of $Q$ fever endocarditis. Antimicrobial Agents and Chemotherapy 49: 2673-2676, 2005.

16. Siciliano RF, Strabelli TM, Paddock CD, Jones TF, Zeigler R, Rodrigues C, Uip DE, Castelli JB, Sampaio RO, Grinberg M, Colombo S, Santos FCP, Nascimento EMM. Culture-negative endocarditis in Sao Paulo, Brazil. Serologic investigation of Coxiella burnetii and Bartonella spp. Clinical Research in Cardiology 96: 411, 2007.

17. Siciliano RF, Strabelli TM, Zeigler R, Rodrigues C, Castelli JB, Grinberg M, Colombo S, Silva LJ, Nascimento EMM, Santos FCP, Uip DE. Infective endocarditis due to Bartonella spp. and Coxiella burnetii: experience at a cardiology hospital in São Paulo, Brazil. Annals of the New York Academy of Sciences 1078: 215-222, 2006.

18. Stein A, Raoult D. Q fever endocarditis. European Heart Journal 16 (suppl B): 19-23, 1995. 